\title{
GENETIC DIVERSITY ASSESSED BY PEDIGREE ANALYSIS IN THE BLANCO OREJINEGRO (BON) CATTLE BREED POPULATION FROM THE COLOMBIAN GERMPLASM BANK
}

\author{
Ricardo Ocampo Gallego ${ }^{1 *}$, Julián Ramírez Toro ${ }^{1}$, John Lopera Peña ${ }^{1}$, Gonzalo Restrepo Castañeda ${ }^{1}$, \\ y Jaime Gallego Gil ${ }^{1}$ \\ ${ }^{1}$ Corporación Colombiana de Investigación Agropecuaria (AGROSAVIA), Centro de Investigación el \\ Nus, San Roque, Antioquia, Colombia \\ * Corresponding author E-mail: rocampo@agrosavia.co
}

\begin{abstract}
The Blanco Orejinegro (BON) breed is one of the seven Colombian Creole cattle breeds, which descends directly from Spanish cattle brought to the Americas during the conquest period. Currently, most of the Creole cattle breeds in Colombia are at risk of disappearing due to the use of foreign breeds and absorbent crosses towards the Zebu and because of this, a germplasm bank was created to preserve them. The BON population kept in this germplasm bank has remained as a closed nucleous over time, and this can affect the conservation of its genetic variability. The objective of this study was to characterize the genetic structure of the BON population maintained in the germplasm bank using pedigree analysis. Genealogical information collected between 1980 and 2019 was used to estimate generational interval, level of pedigree integrity, inbreeding, and its evolution over time. The animals born between 2015 and 2019 were selected as the reference population to estimate the effective population size and parameters derived from the genetic origin probability. The average generation interval for the period studied was 4.58 years, and the general inbreeding was $1.32 \%$. For the reference population, the inbreeding was $2.88 \%$, and the effective population size was 123.75 , while the effective number of founders and ancestors was 55 and 38, respectively. The results indicate that the population has a good genetic diversity and low levels of inbreeding. The use of a larger number of breeder males is recommended to conserve the population over time.
\end{abstract}

Key words: Blanco Orejinegro, BON, Creole cattle, effective population size, genealogy, generational interval, inbreeding, Colombia.

\section{INTRODUCTION}

Genetic diversity has traditionally been defined as the variety of alleles or different genotypes present in a population which reflects the morphological, physiological and behavioral differences that can be seen among individuals and populations (Frankham et al., 2002).

Maintenance of genetic diversity is of great importance in animal breeding because heterozygosity and allelic diversity can be lost at an accelerated rate when there are small, closed and selected populations (Sheikhlou and Abbasi, 2016).
In Colombia, due to the existence of a great variety of agroclimatic regions, the development of a high diversity of native animal and plant species has been favored, including seven Creole cattle breeds as well as three sheep and three swine breeds (Ocampo et al., 2017).

Among the Creole cattle breeds, the Blanco Orejinegro (BON) is the most abundant breed in the country (Fig. 1), which until a few years ago was at risk of disappearing due to indiscriminate crosses with Zebu breeds (Martínez et al., 2012). It is estimated that the current population is comprised by approximately 8,000 individuals, which are distributed in the undulating

Received: 17 October 2019. Accepted: 16 November 2019 


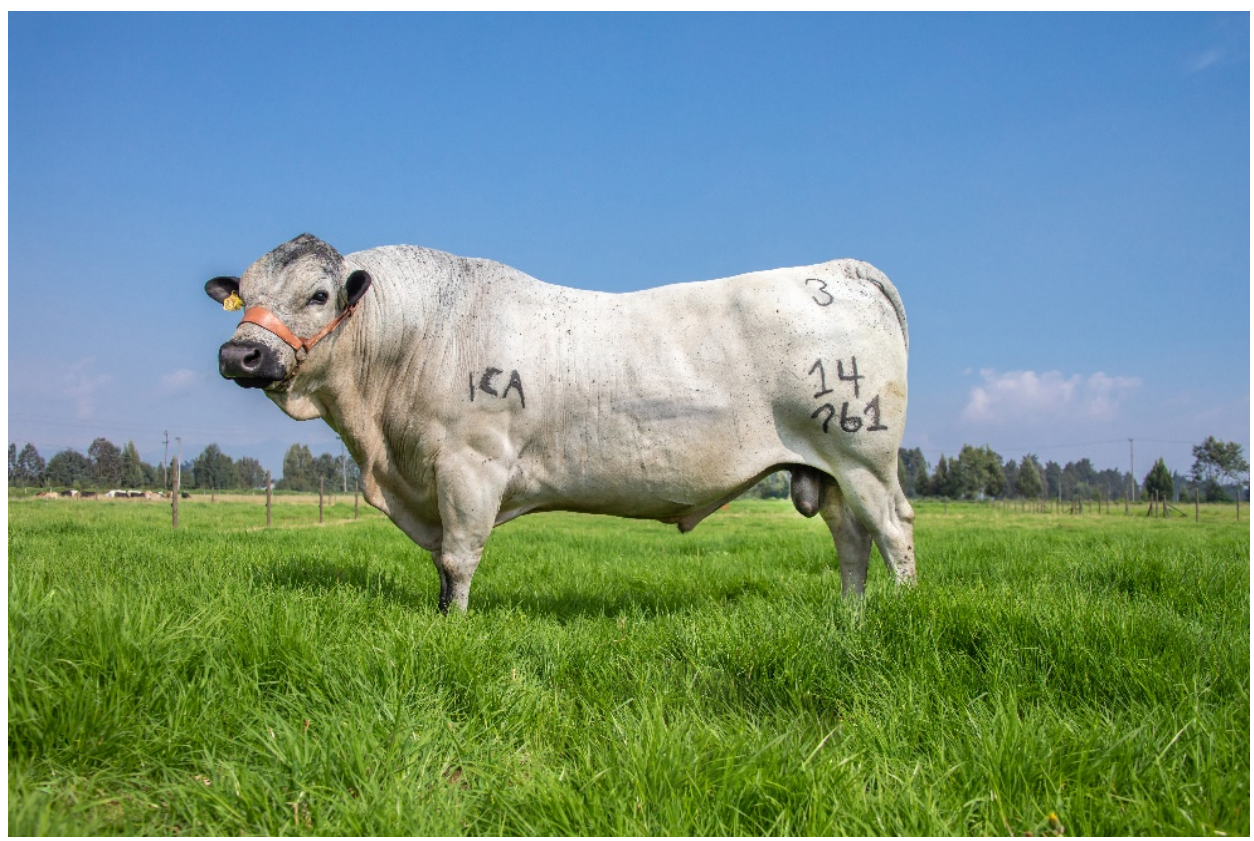

Fig. 1. A male specimen of the Blanco Orejinegro (BON) breed.

and mountainous regions of the Colombian departments of Antioquia, Caldas, Quindío, Risaralda, Tolima, Huila, Valle del Cauca, Cundinamarca, Caquetá and Putumayo.

The Corporación Colombiana de Investigación Agropecuaria (AGROSAVIA) has been the institution in charge of preserving and promoting the use of the indigenous genetic resources of the country, and to that end it established Sistema de Bancos de Germoplasma de la Nación para la Alimentación y la Agricultura (SBGNAA) [System of National Germplasm Banks for Food and Agriculture], a project financed by the Ministry of Agriculture and Rural Development in agreement with Instituto Colombiano Agropecuario (ICA) [Colombian Agricultural Institute].

At present, the Blanco Orejinegro population maintained in the germplasm bank is composed of 430 animals, distributed in eight family groups and managed under a cyclic circular mating system (Nomura and Yonezawa, 1994). However, because it is a closed herd, this situation might generate a considerable increase of inbreeding, which in turn can lead to adverse effects on productive or reproductive characteristics and suitability of the animals (Martínez et al., 2012).

The impact of this breeding management strategy on changes of genetic diversity can be assessed at the genealogical level using the pedigree of the animals and a criterion based on the identical by descent probability of the genes, and a criterion based on genetic origin probabilities (Sheikhlou and Abbasi, 2016).
The objective of this study was to analyze the pedigree information of the $\mathrm{BON}$ breed population kept in the germplasm bank in El Nus Research Center of AGROSAVIA, to quantify genetic diversity and structure of the population in terms of inbreeding coefficent, effective population size, generational interval and contribution of the founders to the current population.

\section{MATERIALS AND METHODS}

\section{Data}

Data were collected from field records of the BON animals maintained in the germplasm bank, and born at the El Nus Research Center of AGROSAVIA (San Roque, Antioquia, Colombia) between 1980 and 2019. Each complete record in the database comprised information such as identification code of the animal, sex, identification of the sire and dam, and date of birth. The database included 4,523 animals $(2,142$ males and 2,381 females). All the base population parameters were estimated considering the reference population, defined as the animals born from 2015 to 2019 ( $n=667)$, which is equivalent to the animals born during the last generational interval.

\section{Generation interval}

The generational interval is defined as the average age of the parents when their offsprings are born, which are subsequently kept for reproduction. This parameter was calculated for 
the four possible genetic paths: father-son, fatherdaughter, mother-son, and mother-daughter. The average generation interval for the population is defined as the average value of the four paths.

\section{Level of pedigree integrity}

The level of pedigree integrity identifies how much of the pedigree information is complete in each generation, and can be calculated from the amount of information that is unknown, i.e., the number of records having unknown parents. The number of generations that contribute to assessing pedigree integrity can be calculated in three ways: i) number of complete generations (given as the number of generations in which both parents are known); ii) number of maximum generations (given as the total number of possible generations if the parents are known or unknown), and iii) number of equivalent generations, which is calculated using equation 1 :

$$
E q G i=\sum\left(\frac{1}{2}\right)^{n}
$$

where $n$ is the number of generations in which the animal is separated from each ancestor with a known record (Maignel et al., 1996). The comparison between complete and maximum generations numbers allows verifying the integrity of the pedigree information, because similar numbers for both indicates the existence of few unknown animals throughout the pedigree.

\section{Genetic origin probability}

When pedigrees were traced to the reference population, the ancestors with unknown parents were considered as non-inbred and nonrelated founder animals. The expected genetic contribution of each founder to the reference population was defined as the probability that a gene taken at random within the reference population comes from a particular founder. The total number of founders $(f)$ contains limited information regarding the genetic diversity of the population because some founders have been used more intensively and, therefore contribute more to the reference population than other founders. Accordingly, the effective number of founders was estimated $(f e)$. This number was defined as the number of founders that contribute equally and are expected to produce the same genetic diversity in the populations under study (Lacy, 1989). The estimation of this parameter allows measuring the balance of genetic contributions among founders. The effective number of founders $(f c)$ was calculated using equation 2 :

$$
f e=\frac{1}{\sum_{k=1}^{f} q_{k}^{2}}
$$

where $(f)$ represents the number of founders and $\left(q_{k}\right)$ is the genetic contribution of the $k^{\text {th }}$ founder to the reference population (Gutiérrez and Goyache, 2005). For a given total number of founders, when genetic contributions of each are balanced, there is the highest effective number of founders.

The main ancestors (founders or not) were estimated using the method proposed by Boichard et al. (1997). The expected marginal contribution $\left(q_{i}\right)$ of the $j^{\text {th }}$ main ancestor was calculated as its expected genetic contribution, regardless of the contributions of the other ancestors. The effective number of ancestors $(f a)$, which is the minimum number of ancestors (including founders and non-founders) required to explain the genetic diversity of the population, was estimated using equation 3:

$$
f a=\frac{1}{\sum_{j=1}^{a} q_{j}^{2}}
$$

Calculated in this way, $(f a)$ is a measure of the genetic diversity that explains recent bottlenecks and, therefore, partly explains the loss of allelic diversity since the founding of the population (Sørensen et al., 2005).

The ratio between the effective number of founders and ancestors ( $f e / f a$ ) helps identifying if the use of breeding animals caused a genetic bottleneck. Values equal or close to one (1) indicate that there is no genetic bottleneck in the population, while values higher than one (1), the effective number of founders is higher than that of the ancestors, indicating a possible genetic bottleneck.

\section{Population parameters related to the inbreeding coefficient Average coefficient of relationship}

The average coefficient of relationship of an animal is the probability that a randomly selected allele of the population belongs to that particular animal. This coefficient can also be interpreted as the representation of the animal in the pedigree (Gutiérrez and Goyache, 2005; Goyache et al., 2003; Gutiérrez et al., 2003). According to Gutiérrez et al. (1990), this parameter is calculated as the average of the coefficients in the row, of the numerator relationship matrix, corresponding to the animal.

\section{Inbreeding coefficient}

The inbreeding coefficient $(F)$ is the probability that the maternal and paternal alleles at a given locus are identical by descent. For its calculation, the algorithm developed by Meuwissen and Luo (1992) was used. The increase of inbreeding by generation was calculated using equation 4 : 


$$
\Delta F=\frac{\left(F_{t}-F_{t-1}\right)}{\left(1-F_{t-1}\right)}
$$

where $F_{t}$ and $F_{t-1}$ are the average inbreeding in the $\left(t_{t h}\right)$ and $\left(t_{t h-1}\right)$ generations, respectively.

\section{Effective population size}

The effective population size $\left(N_{e}\right)$ is the number of individuals that contributed effectively to leaving descendants, transmitting genes to the next generation and maintaining genetic diversity (Gutiérrez and Goyache, 2005). The effective population size was calculated for the reference population using equation 5 as follows:

$$
N e=1 / 2 \Delta F
$$

where $(\Delta F)$ is the relative increase of inbreeding by generation.

\section{Software used}

Pedigree integrity, generational interval, the parameters derived from the gene origin probability, and the population parameters related to the inbreeding coefficient were calculated using the ENDOG 4.8 software (Gutiérrez and Goyache, 2005). ENDOG is a computational population genetics program that performs several genetic and demographic analyzes using information from the pedigree to monitor the changes that occur in genetic variability and structure of the population over time.

\section{RESULTS}

The evolution of born animals per year of birth is presented in Fig. 2. The number of births varied considerably throughout the study period. The highest number of births was recorded in 2015 with 164 births, while the lowest number of births was recorded in 1987 with only 44 births. However, from that year onwards, there was a progressive increase in the average number of births per year.

The average generation interval was 4.58 years. Regarding the average generational interval in each of the four possible paths, the following values were obtained: father-son $=3.72$ years; father-daughter $=3.82$ years; mother-son $=$ 5.46 years; and mother-daughter $=5.32$ years. It is clear that the generational intervals in the fatherson/ daughter paths were lower than the motherson/ daughter intervals.

\section{Integrity level of the pedigree}

The integrity analysis of the pedigree showed that of the 4,523 animals analyzed, the number of animals with both known parents is 4,116, which corresponds to $91 \%$ of the total population. Besides, only 59 animals had a single unknown parent, which corresponds to $1.3 \%$ of the records. On the other hand, the integrity analysis of pedigree for the entire population revealed 13 maximum generations, six complete generations, and 9.21 equivalent generations. Additional information can be found in Table 1 .

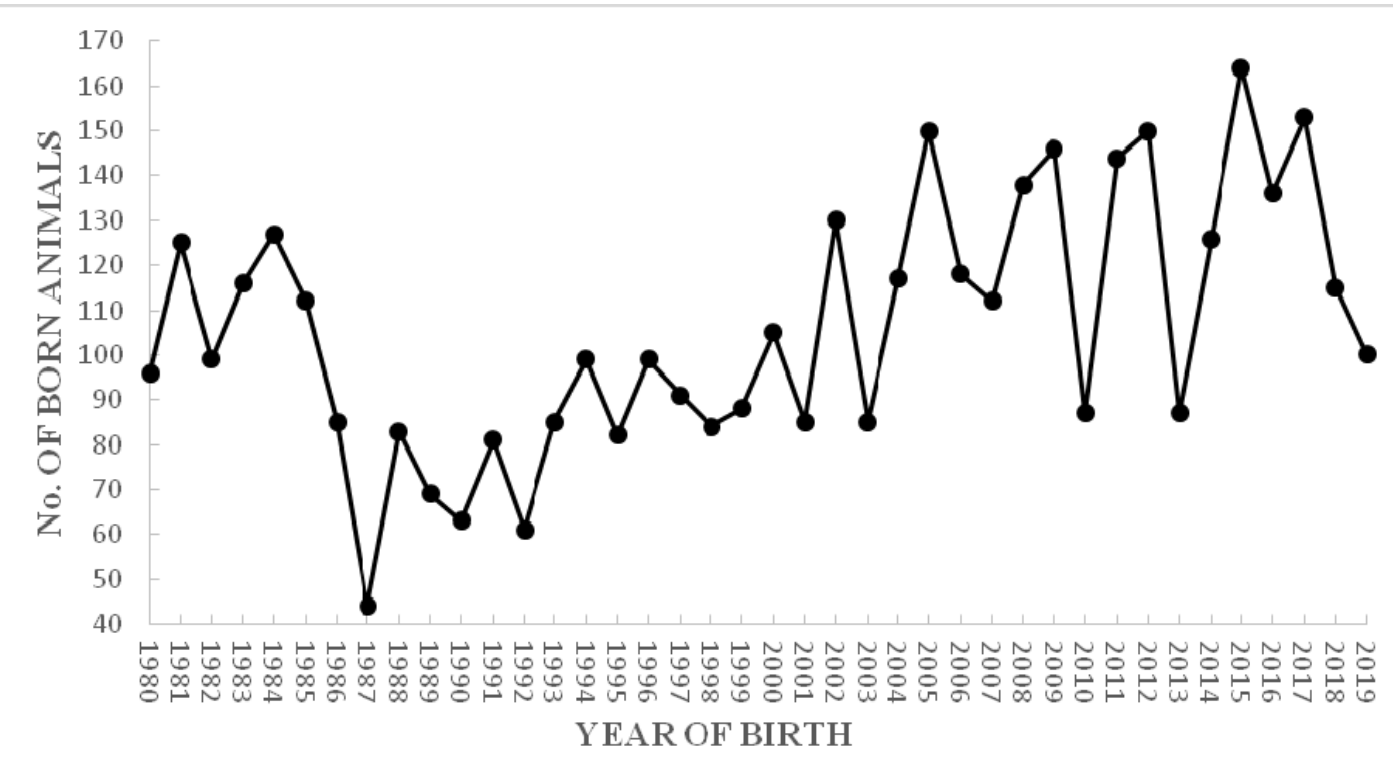

Fig. 2. Evolution of the number of BON calves born from 1980 to 2019. 
Table 1. Pedigree structure in the BON cattle breed population from the Colombian germplasm bank from 1980 to 2019.

\begin{tabular}{lc}
\hline Pedigree structure & Value \\
\hline Number of animals & 4.523 \\
Number of males & 2.142 \\
Number of females & 2.381 \\
Number of fathers & 324 \\
Number of mothers & 1.415 \\
Animals with progeny & 1.739 \\
Animals without progeny & 2.784 \\
Animals with known father and mother & 4.116 \\
Animals with only unknown father & 47 \\
Animals with only unknown mother & 12 \\
Males with unknown father and mother & 78 \\
Females with unknown father and mother & 270 \\
Maximum generations & 13 \\
Complete generations & 6 \\
Equivalent generations & 9.21 \\
\hline
\end{tabular}

\section{Genetic origin probability}

In the referencepopulation, a total of 128 animals were identified as founders, while the effective number of founders for the same population was 55 animals. The number of ancestors that explains $100 \%$ of the genetic variability of the reference population is 121 individuals (founders or not), while 14 individuals explained $50 \%$ of the genetic variability. Regarding the proportion of the effective number of founders and ancestors in the reference population, the value obtained was 1.45 , i.e., close to 1 ; this indicates the absence of possible bottlenecks in the population. Additional information on the genetic origin probability of the reference cattle population from the Germplasm bank is presented in Table 2.

\section{Population parameters related to the inbreeding coefficient}

Average inbreeding for all the animals of pedigree and reference population were $1.32 \%$ and $2.88 \%$, respectively. According to Fig. 3, average inbreeding per year for all the animals in the pedigree of the germplasm bank showed a stable trend until 2001. However, there has been a progressive increase in inbreeding since 2002. In fact, the highest historical inbreeding value in the population was recorded at $3.06 \%$ in 2017.

Table 3 summarizes the number of animals, the average inbreeding coefficient, the percentage of inbred animals, and the average inbreeding coefficient for inbred animals, as well as the average relationship for complete generations. It can be observed that inbreeding as well as the number of inbred animals and genetic relationship increases throughout complete generations. Furthermore, the increment of inbreeding for a complete generation was $0.40 \%$. Likewise, from the fourth generation, all the animals of the population under study are inbred.

Regarding effective population size $\left(N_{e}\right)$, which was estimated based on the inbreeding increase in the individuals of the reference population, the value obtained was 123.75 ; this value is above the minimum effective population size defined by FAO (1998) of 50 individuals as a critical level.

\section{DISCUSSION}

Colombia had an approximate inventory of two million BON cattle heads by 1940. However, the population suffered a drastic decrease by 1999 when the population size was estimated to be around 3,967 individuals, distributed in 27 herds. The main cause of this decrease was indiscriminate crosses with the Zebu breed as well as other breeds imported from Europe (Asocriollo, 2003).

In the germplasm bank of the Colombian nation, births in the population of BON cattle from 1980 to 2017 have remained relatively stable, ranging between 80-130 calves born/year. However, there were years in which there was a reduction in the number of animals born/year, which can be partly explained by the fact that the germplasm bank took part of program called "promotional plan" for several years. This program, which was created by the Ministry of Agriculture and Rural Development of Colombia, promoted the use of creole cattle breeds adapted to the Colombian 
Table 2. Summary of the genetic origin probability parameters calculated for the reference population.

\begin{tabular}{lc}
\hline Genetic origin probability parameter & Value \\
\hline Total number of founding animals & 128 \\
Effective number of founding animals $(f e)$ & 55 \\
Number of ancestors & 121 \\
Number of ancestors that explain 50\% of the genetic pool & 14 \\
Effective number of ancestors $(f a)$ & 38 \\
Contribution of the main ancestor $(\%)$ & 6.55 \\
Ratio $(f e l f a)$ & 1.45 \\
\hline
\end{tabular}

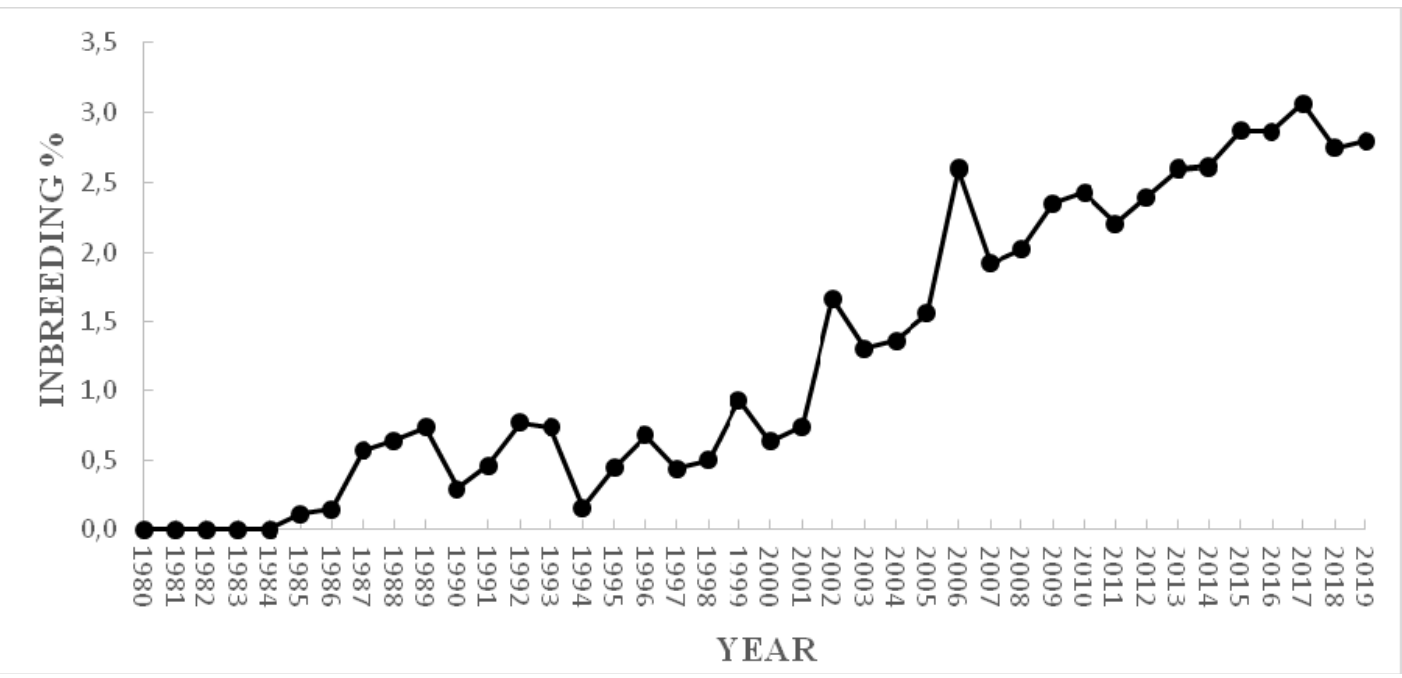

Fig. 3. Evolution of the inbreeding average of the BON cattle population from the germplasm bank from 1980 to 2019.

Table 3. Number of animals per generation $(\mathrm{N})$, average inbreeding coefficient $(\mathrm{F})$, percentage of inbred animals, inbreeding coefficient for inbred animals, average relationship (AR).

\begin{tabular}{cccccc}
\hline $\begin{array}{c}\text { Complete } \\
\text { generations }\end{array}$ & $\mathbf{N}$ & $\mathbf{F}$ & $\begin{array}{c}\text { Inbred animals } \\
\mathbf{( \% )}\end{array}$ & $\begin{array}{c}\text { F coefficient for } \\
\text { inbred animals }\end{array}$ & AR \\
\hline 0 & 409 & 0.000 & 0.00 & 0.000 & 0.005 \\
1 & 902 & 0.001 & 3.88 & 0.023 & 0.014 \\
2 & 809 & 0.007 & 31.15 & 0.022 & 0.030 \\
3 & 821 & 0.015 & 80.76 & 0.018 & 0.038 \\
4 & 812 & 0.024 & 100 & 0.024 & 0.043 \\
5 & 530 & 0.027 & 100 & 0.027 & 0.044 \\
6 & 25 & 0.031 & 100 & 0.031 & 0.046 \\
\hline
\end{tabular}

environment by the country's cattle farmers, aiming at increasing the population size of these breeds, and thus generating useful information to implement a genetic improvement program. Therefore, some of the females and males suitable for reproduction were delivered to cattle farmers. Thanks to this program, the current population of BON breed is estimated at around 8,000 individuals, and is the largest population among the seven Colombian creole cattle breeds. 
Regarding the generational interval, when it was estimated for the BON breed by the four possible paths, it was higher when calculated by the mother-son/daughter paths than when it was calculated using the father-son/daughter paths. The use of the circular mating system in the germplasm bank may be the reason of these patterns, because the selection of the replacement females takes place after the selection of the males, resulting in longer generational intervals for females compared to males.

The average generation interval in the $\mathrm{BON}$ breed of the germplasm bank (4.59 years) was lower than the value found by Martínez et al. (2012), who reported average generational intervals for other Colombian Creole breeds such as San Martinero, Romosinuano and Costeño Con Cuernos of 6.7, 5.7 and 5.4 years, respectively. Furthermore, when compared to the Zebu breeds, the average generational interval found for the BON breed in the current study was considerably lower than that found by Santana et al. (2014), Peixoto et al. (2010), Reis Filho et al. (2010) and Faria et al. (2009), who reported generational intervals for the Brahman, Guzerá, Nellore, and Gir breeds that ranged between 6.95 and 8.93 years. This result shows that individuals of the BON breed in the germplasm bank have shorter generational intervals, which may be an indication of the precocity of the breed.

Regarding pedigree integrity, out of the 4,523 individuals that comprise the pedigree of the germplasm bank, only 59 animals had an unknown father/mother, and for the 348 animals that have both, unknown father and mother; these are the individuals that started the conservation program (founders). Regarding the number of generations obtained from the pedigree, there was no marked difference between the number of maximum (13), equivalent (9.21) and complete generations (6), which means that there is no considerable loss of genealogical information in pedigree individuals. This is in agreement with Santana et al. (2014) and Danchin-Burgue et al. (2012), who conducted studies in populations of Nellore and dairy cows, respectively, and also concluded that this is a key issue because the lack of genealogical data can cause an underestimation of the coefficients of inbreeding and relationship for the average population and the oldest animals.

Regarding the genetic origin probability of the reference population, the proportion between the effective number of ancestors and founders was 1.45 , which indicates that the population has remained stable in terms of the number of animals that contribute effectively, and that has not been affected by bottlenecks. Higher values were found by Martínez et al. (2012) for the Colombian
Creole breeds Costeño Con Cuernos, San Martinero, and Romosinuano, i.e., proportions of founders and ancestors of 1.51, 1.87 and 2.91, respectively. Therefore, these values indicate that in Colombia, the population of Romosinuano cattle was affected by a possible bottleneck. On the other hand, a greater imbalance between the number of founders and ancestors was observed in the studies carried out by Peixoto et al. (2010) in Brazilian Guzerá cattle and by Danchin-Burge et al. (2012) in eight French dairy breeds.

Regarding the inbreeding average of all the animals in the pedigree $(1.32 \%)$ and the reference population $(2.88 \%)$, there has been a progressive increase in inbreeding during the last years. However, this has remained at low levels taking in account that it is a closed population, and has not exceeded the limit recommended by FAO of $5 \%$ for this type of population (FAO 2013). In the analysis of complete generations, both inbreeding and average relationship increase as the number of complete generations does. Nonetheless, the increase of inbreeding by generation $(0.40 \%)$ is lower than $1 \%$, as stated by FAO (2013) and Bijma (2000) to avoid inbreeding depression and the consequent loss of genetic variability in the population (Bernardes et al., 2016; Sheikhlou and Abbasi, 2016; Brito et al., 2013; Ocampo and Cardona, 2013; Tahmoorespur and Sheikhloo, 2011). The effective population size $\left(N_{e}\right)$ suggested by FAO (2013) is 50 individuals. However, Meuwissen (1999) stated that, considering mutations and genetic drift, the critical $\left(N_{e}\right)$ should be between 50 and 100 animals. The estimated $\left(N_{e}\right)$ for the reference population in the current study was 123.75 individuals, which represents a favorable situation for the population, and can be explained by the use of several breeding animals for mating and by avoiding the use of artificial insemination that use fewer males of superior genetics. The $\left(N_{e}\right)$ obtained in this study for the $\mathrm{BON}$ breed was lower than the value reported by Martínez et al., (2012) for the Colombian Creole breed Costeño Con Cuernos (143 individuals). However, the value was much higher than that reported in the same study for the Romosinuano (66.1 individuals) and San Martinero (27.1 individuals) breeds; the latter is at a critical level as indicated by FAO. Similarly, the $\left(N_{e}\right)$ for the BON breed of the germplasm bank was also higher compared to the results reported by Cortés et al. (2014) for Lidia (fighting) cattle in Spain $\left.\left(N_{e}\right)=26.7\right)$, and to those published for Abondance $\left.\left(N_{e}\right)=67\right), \quad$ Tarentaise $\left.\left(N_{e}\right)=71\right), \quad$ Montbéliarde $\left.\left(N_{e}\right)=82\right)$, Holstein $\left.\left(N_{e}\right)=91\right)$, Normande $\left.\left(N_{e}\right)=92\right)$, and Brown Swiss $\left.\left(N_{e}\right)=98\right)$ breeds by DanchinBurge et al. (2012) in France. 


\section{CONCLUSIONS}

The analysis of pedigree information for the $\mathrm{BON}$ breed population kept at the germplasm bank of El Nus Research Center of AGROSAVIA, revealed that, even though $\mathrm{BON}$ breed is a closed population, indicators of genetic variability are adequate, showing efficiency in the use of cyclic circular mating system in closed populations. In terms of the population parameters studied, inbreeding has shown a progressive increase in recent years, but still remains well below the critical level recommended by FAO. However, inclusion of a higher number of breeding males is recommended in each of the family groups in order to prevent further inbreeding increase and maintain the genetic diversity of the population.

\section{ACKNOWLEDGMENT}

The authors would like to thank Corporación Colombiana de Investigación Agropecuaria (AGROSAVIA) and Instituto Colombiano Agropecuario (ICA) for financing the conservation projects and the research in Colombian Creole breeds through public funds.

\section{LITERATURE CITED}

Asocriollo. 2003. Razas Criollas y Colombianas Puras. En Memoria del Convenio 13501. Asociación Nacional de Criadores de Razas Criollas y Colombianas, Ministerio de Agricultura y Desarrollo Rural, Bogotá, Colombia.

Bernardes, D.A., R.P. Grossi, M.E. Savegnago, S.B. Buzanskas, E.P. Ramos, D.G. Romanzini, et al. 2016. Population structure of Tabapuã beef cattle using pedigree analysis. Livest. Sci. 187:96-101.

Bijma, P. 2000. Long-term genetic contributions: predictions of rates of inbreeding and genetic gain in selected populations. $225 \mathrm{p}$. Wageningen University, Wageningen, The Netherlands.

Boichard, D., L. Maignel, and É. Verrier. 1997. The value of using probabilities of gene origin to measure genetic variability in a population. Genet. Sel. Evol. 29:5-23.

Brito, F.V., M. Sargolzaei, J. BracciniNeto, J.A. Cobuci, C.M. Pimentel, J. Barcellos, et al. 2013. In-depth pedigri analysis in a large Brazilian Nellore herd. Genet. Mol. Res.12:5758-5765.

Cortés, O., N. Sevane, J.A. Baro, and J. Cañón. 2014. Pedigree analysis of fragmented population, the Lidia cattle breed. Livest. Sci.167:1-8.
Danchin-Burge, C., G. Leroy, M. Brochard, S. Moureaux, and E. Verrier. 2012. Evolution of the genetic variability of eight French dairy cattle breeds assessed by pedigree analysis. J. Anim. Breed. Genet. 129:206-217.

Faria, F.J.C., A.E. Vercesi Filho, F.E. Madalena, and L.A. Josahkian. 2009. Pedigree analysis in the Brazilian Zebu breeds. J. Anim.Breed. Genet. 126:148-153.

FAO. 2013. In vivo conservation of animal genetic resources. Food Agriculture Organization (FAO). Animal Production and Health Guidelines, No. 14. 270 p. FAO, Rome, Italy.

FAO.1998.Secondary Guidelinesfor Development of National Farm Animal Genetic Resources Management Plans. Management of Small Populations at Risk. 219 p. Food Agriculture Organization (FAO), Rome, Italy.

Frankham, R., D.A. Briscoe, and J.D. Ballou. 2002. Introduction to Conservation Genetics. 619 p. Cambridge University Press, Cambridge, UK.

Goyache, F., J.P. Gutiérrez, I. Fernández, E. Gómez, I. Álvarez, J. Díez, et al. 2003. Using pedigree information to monitor the genetic variability of endangered populations: the Xalda sheep breed of Asturias as an example. J. Anim. Breed. Genet. 120:95-103.

Gutiérrez, J.P., and F. Goyache. 2005. A note on ENDOG: a computer program for analysing pedigrí information. J. Anim. Breed. Genet. 122:172-176.

Gutiérrez, J.P., J. Altarriba, C. Díaz, A.R. Quintanilla, J. Cañon, and J. Piedrafita. 2003. Genetic analysis of eight Spanish beef cattle breeds. Genet. Sel. Evol. 35:43-64.

Gutiérrez, J.P., J. Cañón, y M. Rico. 1990. Aplicación de un método modificado de cálculo del coeficiente de consanguinidad en una muestra del ganado vacuno Frison Español. Arch. Zoot. 39:3-8.

Lacy, R.C.1989. Analysis of founder representation in pedigrees-founder equivalents and founder genome equivalents. Zoobiology 8:111-123.

Maignel, L., D. Boichard, and E. Verrier. 1996. Genetic variability of French dairy breeds estimated from pedigree information. Interbull. 14:49-54.

Martínez, R., R.E. Vásquez, y J.L. Gallego. 2012. Eficiencia productiva de la raza Bon en el trópico colombiano. 214 p. Corpoica, Bogotá. Colombia.

Meuwissen, T., 1999. Operation of conservation schemes. In J.K. Oldenbroek (ed.). Genebanks and the Conservation of Farm Animal Genetic Resources. p. 91-113. DLO Inst. Anim. Sci. Heal. Lelystad, Netherlands. 
Meuwissen, T.I., and Z. Luo. 1992. Computing coefficient of consanguinitys in large populations. Genet. Sel. Evol. 24:305-313.

Nomura, T., and K. Yonezawa. 1994. A comparison of four systems of group mating for avoiding inbreeding. Genet. Sel. Evol. 28:141-159.

Ocampo, R.J., R.A. Martinez, J.F. Rocha, and H. Cardona. 2017. Genetic characterization of Colombian indigenous sheep. Rev. Colomb. Cienc. Pecu. 30:116-125.

Ocampo, R.J., and H. Cardona. 2013. La endogamia en la producción animal. Rev. Col. Cienc. Anim. 5:465-479.

Peixoto, M.G., C.F. Poggian, R.S. Verneque, A.A. Egito, M.R. Carvalho, V.M. Penna, et al. 2010. Genetic basis and inbreeding in the Brazilian Guzerat (Bos indicus) subpopulation selected for milk production. Livest. Sci.131:168-174.

Reis Filho, J.C., P.S. Lopes, R.S. Verneque, R.A. Torres, R.L. Teodoro, and P.L.S. Carneiro. 2010. Population structure of Brazilian Gir dairy cattle. R. Bras. Zootec. 39:2640-2645.
Santana, M.L., R.J. Pereira, A.B. Bignardi, L. El Faro, H. Tonhati, and L.G. Albuquerque. 2014. History, structure, and genetic diversity of Brazilian Gir cattle. Livest. Sci. 163:26-33.

Sheikhlou, M., and M.A. Abbasi. 2016. Genetic diversity of Iranian Lori-Bakhtiari sheep assessed by pedigree analysis. Small Ruminant Research 141:99-105.

Sørensen, A.C., M.K. Sørensen, and P. Berg. 2005. Inbreeding in Danish dairy cattle breeds. J. Dairy Sci. 88:1865-1872.

Tahmoorespour, M., and M. Sheikhloo. 2011. Pedigree analysis of the closed nucleus of Iranian Baluchi sheep. Small Ruminant Res. 99:1-6. 